ing resolutions relating to restriction, which were adopted, viz :

"1. The notification and registration by health authorities of all cases of tubereulosis which have arrived at the infectious stage.

"2. The thorough disinfection of all houses in which taberculosis has occurred, and the recording of such action in an open record.

"3. The establishment of special hospitals for the prevention of tuberculosis.

"4. The organization of societies for the prevention of tuberculosis.

"5. Government inspection of dairies and slaughter houses, and the extermination of tuberculosis among dairy cattle.

"6. Appropriate legislation against spitting into places where the sputum is liable to infect others, and against the sale or donation of objects which have been in use by consumptives, unless they have been thoroughly disinfected.

"7. Compulsory disinfection of hotel rooms, sleeping-car berths and steamer cabins which have been occupied by consumptives, before other persons are allowed to occupy them."

A practical means of limitation of tuberculosis or prophylaxis is thorough drill of the patient, friends and attendants by the physician in charge, and ample rules of technique and literature relating to the disease should be furnished gratis to physicians and nurses by boards of health. The plan of the New York Board of Health, of making bacteriologic examinations gratis for medical attendants, in suspected cases, should not only be generally adopted, but should include other infectious diseases as well.

When we contemplate an annual death rate of 163,500 in the United States from the various forms of tuberculosis, without efficient restrictive measures, we should take courage at reading the following extract from an editorial in our official JovRNAL: "The indisputable fact that its death rate (meaning tuber culosis) has been reduced to one-fifth of its former proportions by rigid enforcement of simple and practicable measures of disinfection, of excretions and discharges of every tubercular patient, and of every material thing liable to be contaminated by such excretions and discharges, is a rift in the cloud through which may be discerned the time when tuberculosis like leprosy and the black death, shall, be of interest merely to the historian of human progress," -(Rohé).

In a recent presidential address before the Medical and Chirurgical Faculty of Maryland, Dr. Rohé says : "The isolation of patients is unnecessary; when the material containing the tubercle bacilli-in these cases the sputa-is destroyed, the consumptive is no longer dangerous to his most intimate associates." Such positive statements by these and many other most competent sanitarians should inspire the consumptive and his friends to the strictest sanitation as a means of self-defense.

Restriction of tuberculosis is not only justified from the standpoint of sociology but it is also justi. fied from a business standpoint. When tuberculosis is viewed in the light of financial losses to the country and the nation, the logic of results of restriction demonstrates the correctness of restriction as a business proposition. It is rather difficult to understand why no material advancement in prophylaxis has been made, as the contagiousness of tuberculosis has had its believers for centuries. It is also a matter of wonder that after the thorough restrictive decrees of the King of Naples more than a cen tury ago, which seemed to be based upon correct views of infection, and so effectual-though in some respects overdone-that the medical world did not take up the cue and that the dictum of the Neapol. itan Kingdom did not mark an important era in the prevention of tuberculosis; to be rapidly followed with more general restriction.

As announced in a circular letter in November, Dr. J. R. Laine, Secretary of the California State Board of Health, at the second annual State Sanitary Convention, held at San Jose, April 16, 1894, (under the auspices of the State Board), offered the following resolution, which was adopted:

"Resolved, That hereafter consumption (and other diseases due to the bacillus tuberculosis) should be included in the list of diseases dangerous to public health, requiring notice by householders and physicians to the local health officer as soon as such disease is recognized."

Advanced grounds are now being taken in the prevention of tuberculosis in many countries in Europe, and in our own country by various State Boards of Health, and by many cities and towns.

In conclusion, permit me to say that the difficulties of restriction of tuberculosis are in fact chiefly im. aginary and pessimistic and will soon give place to reason and thorough sanitation.

\section{TUBERCULOSIS AND ITS PREVENTION.}

Read in the Section on State Medicine, ar the Forty-fifth Annual Meeting of the American Medical Association, held at San Francisco. June 5̃-8, 1894 .

BY WINSLOW ANDERSON, A.M., M.D., M.R.C.P., LOND. ADIUNCT TO CHAIR PRINCIPLES AND PRACTICE OF MFDICINE UNIVERSITY OF CALIFORNIA; MEMBER STATE BOARD OF HEALTH, CAL.

Quarantine regulations are enacted and rigorously enforced in cases of cholera, smallpox and other contagious and infectious diseases, while the most dreadful scourge the human race has ever known-a disease which causes the death of more human lives than any and all other infectious and contagious dis eases combined-is permitted to spread its frightful ravages without the slightest interference from medical, municipal, State or national authorities, and that disease is tuberculosis. Quarantine is declared against epidemics of a hundred or a thousand cases of cholera or yellow fever, and yet no laws reach consumption, although over 150,000 deaths occur annually in the United States from this disease alone. If this enormous death rate from any one disease does not constitute an epidemic, I should like to know what it might be termed.

To indicate how it is contracted-for it is never inherited-it is only necessary to quote such high authority as Prof. Wm. H. Walsh, of Johns Hopkins University, who states that the bacilli of tuberculosis, among other infectious diseases are found in the sputum. This sputum is dried, pulverized and inhaled. The breath itself is seldom contagious so long as it remains moist, but when it becomes dry it is competent to infect those who breathe it. Tuberculosis is also contracted by contact and absorption as well as by food and drink which has been contam. inated by the bacilli.

\section{EARLY HISTORY.}

In 1810 Bayle demonstrated that persons having died of consumption exhibited peculiar grayish nodules in various organs of their bodies. Laennec considered these nodules specific of tuberculosis. 
Virchow named these tubercular deposits "cheesy infiltration or caseation." Scrofulous enlargements such as glands, were later on considered tubercular. In 1865, Villemin discovered that these cheesy, tubercular deposits would, by inoculation, produce tuberculosis in healthy animals. Somewhat later, Klebs and Cohenheim declared that tuberculosis was a specific infectious disease, contrary to the generally accepted theory of Niemeyer, that consumption, in the main, was a chronic non-specific inflammation of the lungs. Afterwards, Koch in 1881 isolated the microörganism which is now proven and accepted by the scientific world as the specinic pathogenic microörganism of tuberculosis.

All wasting diseases of the lungs are not necessarily tubercular. We have chronic bronchitis, bronchorrhea, chronic cirrhosis of the lungs, etc., with more or less expectoration, fever, sweating and emaciation, which are not due to the bacilli tuberculosis, but the vast majority of cases of consumption must be looked upon as tubercular; and if you will look for the bacillus you will nearly always find it.

The tubercle bacilli, as you all know, are small rod-like bodies having a length of about one-fourth to one-half the diameter of the red blood corpuscle, so that it requires from 7,000 to 15,000 of these rodlike vegetable bodies, if placed end to end, and from 50,000 to 75,000 of them, if placed side by side, to measure one inch. The interior of these rods may frequently be observed to contain very minute colorless spots-spots which do not take up the coloring matter usually employed in staining the bacilli. These are the spores, the most dangerous part, as they are exceedingly difficult to destroy. It is more than probable that the bacilli which we discover under the microscope in the sputum of a phthisical patient, are merely the dead shells or carcasses holding the living spores. The staining of these bacilli is exceedingly simple. Any physician having the slightest doubt of his diagnosis should at once resort to the microscope, as the disease can be arrested in its early stages.

The tubercle bacilli will be found in tubercular sputum, lungs, brain, intestines, spleen, liver, kidneys, glands, scrofulous or tuberculous bones, and in the socalled "lupus," which is in fact nothing but a tuberculous skin. The bacilli are frequently found in chickens, dogs, monkeys, guinea pigs and cattle. "Pearly distemper" of cows is now definitely known to be tuberculosis.

\section{HOW DOES TUBERCULOSIS AFFECT MAN?}

It is now agreed that tuberculosis can not, like syphilis, be born in the infant. It must be acquired. Therefore, if acquired, it can and should be prevented. Dr. Billings says that in consumption the specific germ is very rarely, if ever, transmitted; inheritance giving only a special susceptibility to its action. The effect of occupation and bodily condition also plays an important part. This is proven by Dr. Biggs, who shows that out of every 1,000 deaths among farmers only 103 die of tuberculosis, while out of the same number of deaths among printers, 460 die of the disease. According to a report recently sent into the Academie de Medicine, in Paris, giving the statistics of 662 towns in France it is shown that consumption increases in proportion to the size of the towns, viz :

$$
\begin{aligned}
& \text { INHabitasts. } \\
& 5,000-\text { (less) } \\
& 5,000-10,000 \\
& 10,000-20,000 \\
& 20,000-30,000 \\
& 30,000-100,000 \\
& 100,000-430,000 \\
& \text { Paris }
\end{aligned}
$$

MORTALITY FROM PHTHISIS.

$\begin{array}{llc}2.00 & \text { to } & 1,000 \\ 2.16 & \text { " } & \text { " } \\ 2.71 & \text { " } & \text { " } \\ 2.88 & \text { " } & \text { " } \\ 3.05 & \text { " } & \text { " } \\ 3.63 & \text { " } & \text { " } \\ 5.00 & \text { " } & \text { " }\end{array}$

Fourteen per cent. of all deaths is trom tuberculosis. Tubercular diseases play sad havoc in every civilized country in the world. Statistics show that about one-seventh of all deaths from all causes, is due to this same tubercle bacillus. This fact should be firmly impressed upon the mind of every physician and sanitarian, also that an acquired disease must be a preventable one. One-quarter of all deaths occurring between the ages of 15 and 30 years, according to Dr. Biggs, is due to tuberculosis. This would seem to increase the percentage even more, for many children die in infancy and many people die in old age of causes other than tubercular. During the twentyfive years ending 1886, the average annual deaths in England from collsumption reached the enormous number of 50,000 . During any one year in the United States over 150,000 people die of this disease. And yet we are bound to admit that the disease is a preventable one. Over 30,000 deaths from tuberculosis occurred in New York city during the five years ending Jan. 1, 1893, while all the other contagious and infectious diseases combined, including smallpox, typhus, typhoid, scarlatina, diphtheria, measles and whooping cough, only caused the death of 21,000 during the same period.

The vast majority of cases of phthisis occur in the lungs - why? Because the germs are drawn in during inspiration. Inoculation experiments prove that the first expression of the disease takes place at the site of its inoculation. Extension may then be rapid or slow and become general or remain localized. If inoculation be practiced in the anterior chamber of the eye, the first tubercular nodule will appear on the iris. If it be in the abdominal cavity, there is first a tuberculosis of the abdominal glands and peritoneum. Should the bacilli enter a wound or a scratch on the hand, the first manifestation of tuberculosis will be seen in the nearest lymphatic gland. Consequently, if the germs are breathed into the lungs we have first a tuberculosis of the bronchial glands and lungs.

For several years, Tappeneiner and others, powdered tubercular sputum in the Pathological Institute in Munich and had different animals inhale it. In every case the animal experimented upon became tuberculous. Domestic animals also play an important part in the production of tuberculosis in man. Chickens will eat the sputum of phthisical patients and contract the disease. By eating under-cooked chickens, tuberculosis may be communicated to man, although the disease is claimed to be slightly different. Dogs in like manner become consumptive and may readily communicate the disease by licking the mouth. Fissures and excoriations of the skin may also become infected. The wearing of clothing, earrings, etc., previously worn by consumptives may spread the disease. Laundrywomen have been known to contract the disease from washing infected cloth. ing. Consumptives occupying public positions, such as clerks in post-offices, banks and the like, are dangerous to public health. Clerks in grocery stores and dry goods establishments should not be con- 
sumptive, as the dry sputum might easily infect the food and the wearing apparel which they handle. Meat and milk often spread the disease. Cattle frequently become consumptive as manifested in the "pearly distemper," which, it is estimated, affects at least 3 per cent. of all cows. Their meat, as has been proven by Strümpell, is capable of communicating tuberculosis by infecting the intestinal glands with the uncooked bacilli. Billings assures us that onehalf to 1 per cent. of all meat sold for food is tuberculous. More frequently, however, the communication is produced by diseased milk. Palleske in Virchow's Archix., concludes from a series of experiments that microörganisms are found in 50 per cent. of human milk. Cow's milk frequently contains bacilli tuberculosis and nearly al ways when the ndder presents pearly nodules. This will no doubt explain the why so many children die of tubercular meningitis and consumption of the bowels, and yet we have no systematic scientific examination of milk in any part of California. For that matter we have no scientific inspection of any article of food that we consume. Is it any wonder that one-seventh of our deaths is from tuberculosis? One sometimes wonders how it is so many escape! It can readily be seen how easily persons having weakly strumous tendency or diathesis inherited from sickly or drunken parents may become tuberculous. They are certain to breathe in the germs, if not at home from some member of the family, then from the air in the street cars, railway carriages, churches, theaters, the streets and public highways which are sure to contain the bacilli, so long as that filthy habit of spitting is permitted. Our modern sweeping machines are excellent microbe disseminators. Those in San Francisco can be particularly recommended for that purpose.

There is every reason to believe that man becomes th infected principally from the sputum of phthisical patients which dries upon the ground, on the floor, linen and other objects. It becomes powdered, and with the dust particles the bacilli float about in the air. Thus we see how easy it is for infection to take place. Sternberg says there can be no doubt that a large proportion of cases of tuberculosis in man results from the respiration, by susceptible individuals, of air containing the bacilli in suspension in a desiccated condition. He also asserts that the germs of tuberculosis may remain in the air for many months and retain their vitality until they find a favorable nidus for multiplication.

\section{BACILLI IN AIR AND EARTH.}

According to Billings, bacteria are persistently present in the lower stratum of the atmosphere we breathe, just as they are nearly always found in the upper stratum of the earth. These statements hold good with the exception of high altitudes, mid-ocean and polar regions. Tuberculosis is rare over 10,000 feet and never found over 16,000 feet elevation.

The bacilli most frequently found in the air and in the earth are those of tuberculosis, malignant edema, tetanus, summer diarrhea, anthrax, malaria, diphtheria and cholera. Dr. Osler has estimated that from one and one-half to four billions of bacilli are expectorated daily by every well marked case of phthisis. Carnet examined the dust on the floor, on the walls, in the curtains, etc., in houses previously occupied by phthisical patients, and found it teeming with bacilli. When these were injected in to guinea- pigs, consumption was rapidly established. This is about what we should expect. How could it be otherwise? And yet we move in to these houses and occupy the very rooms without knowing or caring who occupied them previously. In prisons the mortality from consumption often reaches as high as 50 per cent. of the total number of deaths. This is easily explained when we remember that the rooms are infected with the deadly germs.

The Imperial Board of Health of Germany have been conducting experiments with dust taken from the floors, walls and seats of passenger cars. They examined forty-five compartments of twenty-one cars and inoculated with the dust so obtained one hundred and seventeen animals. Some of these died within a few days of various contagious diseases, before there was sufficient time to develop phthisis; three of those remaining had tuberculosis when killed five or six weeks after the inoculation; 78,000 bacteria per square inch were found on the floor of a fourth class car, and from 16,500 to 34,400 for the same space on the first, second and third class.

\section{INTERMARRIAGE,}

Intermarriage of consumptives is one of the most baneful practices modern civilization countenances. Hundreds of deaths occur annually from this cause alone. Not only is the offspring weakly, puny and prone to contract tuberculosis from one or both parents soon after birth, but the husband or wife even if perfectly healthy, will contract the disease from the sick one. I recently saw this exemplified in my own practice.

In 1874 Dr. Herman Weber furnished some startling statistics regarding the transmission of consumption between husbands and wives. He records thirty-nine husbands more or less tainted with the disease who had married healthy wives, nine of whom died with consumption. These nine husbands lost eighteen wives among them, viz: three lost one each; four lost two each; one lost three and one lnst four; all of these women were healthy previous to their marriage and died within two years thereafter of consumption.

Ten years later the British Medical Association, wishing definite information on the subject, communicated with medical men in various parts of the world, and received returns to the effect that in the majority of cases the husbands imparted the contagion to their wives, but occasionally the rule was reversed. Servants and nurses contracted the disease from their mistresses and from each other. One case was cited of a consumptive dressmaker who had three apprentice girls from different villages and without any consumptive diatheses, who took turns in sleeping with her. In less than two years these three girls died of consumption.

Compare the foregoing conditions with the care we take in breeding horses and dogs. We go to any expense and troubie to breed healthy full.blooded horses. Stables of palatial pretensions are erected for them in the most salubrious climates. A veterinary surgeon visits them frequently, inspects their food and directs their exercise and the hygienic conditions under which they live. Dogs are similarly cared for and tended and yet, sad to relate, no such care, attention nor prophylaxis is attempted in regard to the human race. It is indeed a sad commentary on the value we place on one of God's noblest creations 
when we have to chronicle the fact that more care and more thousands of dollars are expended on a horse or a dog than on the life of a human being. The horse and the dog are carefully mated and cared for during gestation, while man, in any condition, is permitted to marry whom he pleases although loved ones are carried to the grave by the hundreds, and the soil for scrofula and tuberculosis is prepared for generations yet unborn by such unwise, unjust and unjustifiable marriages.

\section{IMPURE FOOD.}

Fully as dangerous as the foregoing is the matter of impure food. Last year I had the honor of pointing out, in a paper read before the Sanitary Convention of the State of California, that much of our food supply was unfit for use, as it had not been properly examined. A still greater evil exists in our milk supply of this and many other cities. I have examined many samples of milk, and I am bound to confess that very few of them came anywhere near the standard prescribed in England or Germany, or the standard for pure milk in our own country. But the most dangerous consideration is that of tuberculous milk. Of this $I$ found more than one sample. Several other investigators have corroborated my researches. It is now conceded and capable of demonstration that from three to five cows in every one, are suffering with tuberculosis.

Dr. P. H. Bryce in his report presented to the Provincial Board of Health Feb. 15, 1894, says that from 2 to 3 per cent. of the cattle in the State of New York are afflicted with tuberculosis. This means that there are over 1,200,000 head of cattle in the United States which should be killed. Dr. Bryce further states the relative prevalence of tuberculosis in cattle in different countries to be 4.5 per cent. in Berlin, 9.5 per cent. in Upper Siberia, and 12.22 per cent. of those slaughtered in England under the Pleuro-Pneumonia Act of 1890 .

The State Board of Health of California under its distinguished President, Dr. C. A. Ruggles, found more than 50 per cent. of the cows used at the Stockton Insane Asylum infected with tuberculosis in 1894.

Their milk contains the bacilli of the most dread. ful foe the human race has to contend against, and yet we have no scientific milk inspection. Butter may also contain the germs as we all know meat does. Who can tell how many cases of tabes abdominalis are due to the bacilli-laden milk the infant drinks? Consumption of the bowels is not an infrequent disease in San Francisco, and it has been fully demonstated that tuberculous milk produces the fatal disease. Not only is this the case with infants but also with grown people. Dr. Olliver reports an instance requiring more than a passing notice. It was in a boarding school for young ladies. In the course of some little time several of the scholars were taken ill with tuberculosis and removed to their homes. Sanitarians inspected the premises. The plumbing was good, the air salubrious and the buildings were properly ventilated. The food and water were found to be wholesome and no cause could be assigned for the disease. Still one after another came down with abdominal or pulmonary tuberculosis until the number had reached twelve. Everything had been examined excepting the milk. This was the last article of food thought of, as it was produced from a large dairy not far away. However, upon investigation the milk was found to contain tuberculous germs, and as. milk was cheap and presumably healthy, the young ladies of the school had been fed upon it ad libitum. The cows were next inspected and many of them were found to have "pearly distemper" or consumption. The owner of the herd was forced to withdraw his milk from the market, and not knowing what to do with it he fed it to his pigs. The records show that even the pigs could not withstand the bacilli tuberculosis, as all died from the disease within a year. Suffice it to say that as soon as healthy or boiled milk was supplied to the young ladies' school there was no more consumption. It is asserted, and rightly so, that if bacilli are introduced into the stomach of a healthy individual, they are usually digested or rendered inert by the gastric juice, but how many infants who drink milk are not healthy? How many have the necessary resisting power? We all know that there are thousands upon thousands of susceptible cases in every large city, and these are the first to succumb. It is all wrong, it is unscientific, nay more, it is absolutely criminal to allow such matters to go unchecked. We owe it to ourselves, our friends, and to the community at large to enter our solemn protest against the consumption of articles of food, and especially of milk, until they have been carefully examined by competent authorities. Every Board of Health should have the power to appoint competent chemists and bacteriologists to investigate this matter, and thus lessen the mortality from tuberculosis.

\section{ISOLATION OF TUBERCULOUS PATIENTS.}

A hundred years ago a law was enacted in Naples which compelled physicians to report all cases of consumption to the Health Department under penalty of a fine of three hundred ducats; a second of fense being punishable by ten years' imprisonment. In this way Naples has reduced her mortality of consumption 90 per cent. Improved hygienic conditions and isolation of tuberculous patients in England, has reduced the mortality 50 per cent. within the last few years. Philadelphia, during the eight years just passed, has reduced her mortality from phthisis 20 per cent.

The disposal of consumptives both living and dead is another subject of considerable importance. There can not be the slightest doubt that consumption is communicable from one person to another in the various ways indicated. It can not, therefore, be denied that every consumptive becomes a danger to those around him-a danger to public health. What shall be done with him? Shall we, as intelligent physicians, fully aware of the danger, prostrate ourselves before Allah as do the good Mohammedans in times of cholera epidemic and say: "Let thy will be done; there is no God but Allah?" or shall we stand calmly by with our hands folded and our face to the sun, as do the people of India, imploring protection from Brahma and Vishnu the creator and preserver, that Shiva-the destroyer-does not annihilate us? Rather, shall we not as men, imbued with Western thought and civilization and freed from the trammels of oriental and occidental superstitions, assert our rights as teachers of the healing art, determine what had best be done with the unfortunates who become consumptive? I say, yes, we must protect the public health. In that event we are bound to isolate and care for consumptives so that the disease does not 
spread. California is rapidly becoming a great sanitarium for these unfortunates. If we.allow them to come to our shores to seek health, is it not proper that we should protect the healthy? Should we not protect our fair sunny shore with its balmy atmosphere from becoming a cesspool of contagion and infection? How can this be accomplished? Not by denying consumptives to come to our fair land to be cured. No; but by proper isolation; by proper regulated sanitaria, giving them all the advantages of climate and hygienic surroundings, rationally constructed buildings and scientific medication.

CREMATION OF CONSUMPTIVES.

What shall be done with the bodies of those who die of tuberculosis? It is estimated that 32,000 persons die annually to every million that are living. This means that $48,000,000$ people die annually, of which one-seventh, or about $7,000,000$, die of tuberculosis. These figures are alinost incomprehensible. Estimating seventy-five pounds to each consumptive's body there are about 300,000 tons of bodies for burial annually. Fortunately they are not all buried; many of them are, as they should be, cremated. The bacilli of tuberculosis have been found in old cemeteries in which no inhumation had been practiced for over twenty-five years. Pasteur and others have proven that the earthworms bring the bacilli to the surface of the soil where they can be found in all cemeteries. It takes from five to twenty years for human bodies to decay, and as millions upon millions of consump. tive bodies are continually being added to those already buried, the result must be self-evident, and instead of one seventh of our population dying-as they do now-of tuberculosis, it must of necessity increase. Something must be done, and that before it is too late.

The Mosaic laws direct that all lepers be driven out of their houses and their effects burned. What leprosy was to Moses and his people, and is to-day to the Hawaiians, tuberculosis is to the American people -the greatest scourge the human race has ever encountered.

RULES FOR THE PREVENTION OF TUBERCULOSIS.

Comprehensive and efficient means should be adopted for the prevention of tuberculosis. I will recommend the following:

1. Educate the public to a proper understanding of the communicable character of tuberculosis. Teach the people how they can avoid contracting the disease themselves and how they can prevent transmitting it to others.

2. The promiscuous expectoration of consumptives should be prohibited. The sputum should be received into a 10 per cent. solution of carbolic acid, or an acid solution of bichlorid of mercury, 1 to 1000. If at any time this be impracticable, the sputum may be collected on paper napkins or handkerchiefs which must be burned before they become dry. Under no circumstances should a phthisical patient be allowed to spit on the floor or on the streets.

3. Let every physician employ systematic bacteriologic examiuacion for the early diagnosis of the disease, and let us inaugurate compulsory registration of all cases of tuberculosis.

4. It should be made compulsory to have careful and thorough disinfection of all houses, apartments, penal and reformatory institutions, carriages, street and railway cars, steamships, theaters, churches, etc., which have been exposed to infection from phthisical patients.

For disinfection of rooms I would recommend sulphur acid gas obtained hy burning one ounce of suiphur to every ten cubic feet of space, or chlorin gas to saturation. Shut all doors, windows and crevices for four hours, then let in the fresh air and scrub the walls, floor and articles of furniture with the acid bichlorid solution (bichlorid of mercury 3ij, tartaric acid 3 ii to the gallon of water, or $3 i j$ each of $\mathrm{HgCl}_{2}$ and permanganate of potassium to the gallon). Remove all wall paper if it can not be washed or painted. Thoroughly boil or steam all bedding, carpets, curtains, etc., for at least one hour.

5. Under no circumstances should the stools of tuberculous patients be emptied into the sewers until they have been thoroughly disinfected. The intestinal glands are frequently implicated in tuberculosis, and the dejecta often teem with bacilli; therefore all discharges should be received into a solution of eight ounces of carbolic acid to the gallon, or four ounces of chlorid of lime to the gallon of water.

6. Enact regulations prohibiting tuberculous individuals from rollowing vocations that may expose others to the danger of infection. The sputum may dry on their beards or clothing and then be disseminated. For the same reason, consumptives should avoid kissing and even hand shaking to protect those near and dear to them. All dishes and drinking cups should be used by the patient exclusively and should never be mingled with those in use by other members of the family. The promiscuous use of public drinking cups in schools, cars, streets and churches, can not be too severely condemned, as contagion is possible from this practice.

7. Tuberculous mothers should not nurse their children. In fact, consumptive people should not be permitted to marry.

8. There should be established careful scientific examinations under city and State control, of all milk, meat and other articles of food sold. All animals suffering from tuberculosis, anthrax, septicemia, glanders, cattle plague, sheep-pox, swine plague, foot and mouth disease, acute pneumonia, actinomycosis, dropsy and rabies, should be killed and at once cremated.

9. Consumptives should always be isolated, and there should be established under State control public hospitals and sanitaria for the segregation and isolation of the consumptive poor, where they could live under the best hygienic laws, receive proper food and judicious medicament.

10. All persons having died of tuberculosis should be at once wrapped in sheets wrung out of bichlorid solution, and cremated as soon as practicable. If this be not possible, then they should be buried with quick-lime, as the bacilli do not die with their host, but have been found in cemeteries from two to twenty-five vears after inhumation.

Is it not our duty to prevent the ravages of tuberculosis and thereby save over 150,000 lives annually in the United States? Are we not bound by our obligations to ameliorate suffering and prevent loss of life, and this can be accomplished by isolation, proper hygiene and disinfection. That tuberculosis is contagious-even from man to wife, no one but the ancient, non-progressive physician will deny-preven- 
tjon is not only possible, but comparatively easy, or carried some of the contagion on his hands. There and it is demanded of us as physicians and sanita- are many places on the hands that escape the scrurians guarding the public health.

CLEANLINESS THE CHIEF ANTISEPTIC.

Read in the Section on State Medicine at the Forty-fifth Annual Meeting of the American Medical Association, held at San Francisco. Iune 5-8, 1894.

BY C. F. ULRICH, A.M., M.D. WHEELIXG, W, VA.

In these days of bacteriologic investigations much time and study is necessarily devoted to the prevention of disease by destroying the bacilli that have entered the human body or preventing their entrance. The latter of these methods is to be preferred where it can be done, and it is the province of this paper to show that this may be accomplished much more thoroughly and satisfactorily by perfect cleanliness than by the use of so-called antiseptics. First, a few words regarding the physician and surgeon in whose practice cleanliness is an absolute necessity. This branch of my subject, although not precisely to be classed with State Medicine has nevertheless a bearing on it, and will form a suitable introduction to the main theme. Let us first speak of the surgeon and his work, in which the necessity of cleanliness is most apparent. If the surgeon will see that his hands, his person and his clothing are clean, that his instruments have always been thoroughly cleansed immediately after using them and are then cleansed again just before using, much difficulty will be avoided. Drenching the body and its exposed cavities with antiseptic fluids is not always the best thing to do, as injury is sometimes done by the absorption of the poisonous articles used as antiseptics. When a laparotomy is performed in which the interior of the abdomen is exposed to the outer air; when the interior organs are handled by the surgeon or his assistants: when instruments and sponges are introduced into the cavity and come in contact with healthy organs, the necessity of perfect cleanliness becomes apparent even to an inexperienced observer. I have seen surgeons who prided themselves on their extreme care in preserving antisepsis, make lamentable blunders by allowing sponges that had been in contact with diseased parts, removed from the abdominal cavity, to be used again in cleansing the cavity after the operation, preparatory to closing it up. Many little errors of that kind, escaping observation at the time, contribute to unfortunate results which are then ascribed to something else. A few words about the physician before referring to the main topic. Here cleanliness is just as important as in the case of the surgeon, although not always so carefully observed. See the number of cases of puerperal peritonitis caused by the carelessness of the accoucheur in handling the puerperal woman with unclean hands or with imperfectly cleansed instruments. I knew a case of a physician who was skilful, amiable and generally beloved, compelled to abandon the practice of medicine because, during one season, almost every case of obstetrics he attended was followed by puerperal fever, fifteen of which died within the space of a few months. Now there is no doubt in my mind that he carried the disease from one patient to another by a want of proper attention to cleanliness. He either failed to clean his instruments thoroughly when he used them, tiny of the owner, even when he employs frequent lavations; as under and around the nails, between the fingers, etc. The thermometer may carry disease when used in the mouth, if it is not carefully cleansed before and after using. In treating contagious and infectious diseases absolutely perfect cleanliness will do much toward preventing infection of the patients who are seen afterwards; the hands, the clothing, the hair and beard of the doctor may do much mischief if not kept perfectly clean.

We will now approach our main subject, the prevention of disease by cleanliness, so far as this can be controlled by the public authorities. Disease is undoubtedly propagated by germs, bacteria, micrococci, bacilli, or whatever they may be called. These germs may be conveyed into the body by the air passages or by the alimentary canal. In regard to the former, many would say that legislation can do nothing to purify the air. This, however, is not true. Consider the sewer gas, the exhalations from manure piles, the foul smells from shallow or full privy vaults, the odors from reeking back yards and alleys, and you will find them filling the air with all kinds of disease germs. When there is any talk of a prospective invasion of cholera, how all the papers teem with cries for a general cleaning up! How the health officers and inspectors begin to bestir themselves, ordering the people to clean up their premises, throwing copperas and other alleged antiseptics into holes from which issue foul smells, not knowing, perhaps that about all the effect these so-called antiseptics have on the bad air is to substitute another smell, so that the original one is not perceived. If the health officers and the health boards under whose authority they serve, instead of getting spasmodic fits of cleaning up, would exercise eternal vigilance to prevent the accumulation of filth, would have the plumbing of houses, the sewer system leading from the dwellings to the streets regularly inspected; if they would devote time and labor to the proper construction and maintenance of the sewer system in the streets of their cities; if they would appoint men to attend to this business who have made this work a special study, instead of making their appointment a means of bestowing political patronage upon their favorites, there would be infinitely better results.

In a paper I read before the Wheeling Medical Society, I spoke of the air as one of the media through which the bacillus of typhoid fever is conveyed into the system. This was controverted by several members who have had a bacteriologic training, on the ground that the bacillus of this disease can only be propagated in the alimentary canal. Admitting this hypothesis I still maintain my position. We will suppose that the excreta from a fever patient have been deposited upon the surface of the ground, or have found their way there from an imperfect receptacle, what becomes of it ? It mingles with the soil and much of it is converted into dust. This dust pervades the atmosphere and is inhaled by people who move about in the air thus polluted. "But," says the objector, "the lungs do not form a suitable nidus for the bacillus of typhoid fever." Granted. But what becomes of the dust that clings to the cavity of the mouth, the palate, the pharynx, the upper part of the esophagus? By the next drink of water or any other fluid that is swallowed, the whole of it 